\title{
The Prevalence of Blindness, Visual Impairment and Cataract Surgery in Tuoketuo and Shangdu Counties, Inner Mongolia, China
}

\author{
Baixiang Xiao ${ }^{1,2 *}$, Jinglin Yi' ${ }^{1}$, Hans Limburg 3 , Guiseng Zhang4, Richard Le Mesurier5, \\ Andreas Müller ${ }^{6}$, Nathan Congdon², Beatrice Iezzi ${ }^{5}$ \\ ${ }^{1}$ Affiliated Eye Hospital of Nanchang University, Nanchang City, China \\ ${ }^{2}$ Zhongshan Ophthalmic Center, Guangzhou City, China \\ ${ }^{3}$ London School of Hygiene \& Tropical Medicine, London, United Kingdom \\ ${ }^{4}$ Inner Mongolia Red Cross Chaoju Eye Hospital, Hohhot, China \\ ${ }^{5}$ The Fred Hollows Foundation, Sydney, Australia \\ ${ }^{6}$ World Health Organization, Western Pacific Regional Office, Manila, Philippines \\ Email: ${ }^{*}$ xiaobaixiang2006@126.com
}

Received 26 November 2014; accepted 10 February 2015; published 15 February 2015

Copyright (C) 2015 by authors and Scientific Research Publishing Inc.

This work is licensed under the Creative Commons Attribution International License (CC BY).

http://creativecommons.org/licenses/by/4.0/

(c) (i) Open Access

\section{Abstract}

Aim: A population-based survey was conducted in Tuoketuo and Shangdu Counties in Inner Mongolia Autonomous Region, China, in the Autumn of 2010, to assess the prevalence and causes of blindness and visual impairment of people aged 50 years and over. Methods: Random cluster sampling was used to select 82 clusters of 50 residents in the 2 counties. Each survey team included an ophthalmologist, a nurse and a coordinator, who went to door to door in each cluster to identify eligible people. A torch, direct ophthalmoscope and portable slit lamp were used for eye examination. Visual acuity (VA) was tested for each eye of every subject. Those with VA below 6/18 in either eye were examined and causes identified. Results: The survey identified a prevalence of blindness in people aged $50+$ in Tuoketuo of $1.2 \%$ (95\% Confidence Interval: $0.7 \%-1.7 \%$ ) and in Shangdu of $1.4 \%$ (95\% CI: 1.0\% - 1.9\%). Cataract was identified as the leading cause of blindness (BL) and severe visual impairment (SVI), and uncorrected refractive errors were the major causes of moderate visual impairment (MVI) in both counties. Over two thirds of blindness, SVI and MVI were identified as avoidable. Conclusions: The prevalence of blindness in people aged $50+$ in Tuoketuo and Shangdu was low compared to other studies conducted in China [1] [2]. The prevalence of blindness of people aged 50 years and over could be reduced by up to two thirds

*Corresponding author.

How to cite this paper: Xiao, B., Yi, J.L., Limburg, H., Zhang, G., Le Mesurier, R., Müller, A., Congdon, N. and lezzi, B. (2015) The Prevalence of Blindness, Visual Impairment and Cataract Surgery in Tuoketuo and Shangdu Counties, Inner Mongolia, China. Open Journal of Ophthalmology, 5, 23-30. http://dx.doi.org/10.4236/ojoph.2015.51005 
through better eye services in the two study areas.

Keywords

RAAB, Prevalence of Blindness, Cataract, Cataract Surgical Coverage, Survey, Inner Mongolia, China

\section{Introduction}

The World Health Organization (WHO) estimated that in 2010, there were 39 million blind people and another 245 million visually impaired globally [3]. 90\% of people with visual impairment live in developing countries and over $80 \%$ of visual impairment is avoidable or treatable [4]. China has a total population of 1.4 billion in 2009, of whom an estimated 8.248 million were blind [3] — the largest of any country in the world for its number of population, and accounting for $20.9 \%$ of the world's blind. China is also estimated to have the world's most rapidly ageing population [5]. By 2020, the country's elderly population over 60 years is expected to increase by $90 \%$ and reach 240 million people nationwide. As the population ages, it is expected that more people will suffer from cataract. Despite this fact, the cataract surgical rate (CSR) in China is comparatively low, less than 800 in 2010 [6].

The Inner Mongolia Autonomous Region is located in northern China, and is geographically the third largest province in the country. Internationally, it borders Mongolia and Russia. The population density is among the lowest in China, and the geography is high altitude, relatively infertile and drought-prone. Administratively, the region is equivalent to a province, and is divided into 9 alliances (equivalent to prefectures in other provinces), approximately 87 counties, and 13 city-districts.

The population in Inner Mongolia was 24 million (2010), of which 53\% lived in rural areas, and 52\% were male. Life expectancy in Inner Mongolia was 70.7 years in 2005 [7]. Tuoketuo County is located in about 2 - 3 hours drive distance south west of Hohhot, the region's capital city. Shangdu County is at about 6 hours drive way east of Hohhot—closer to Beijing.

In Inner Mongolia, there were about 400 eye doctors. Although the ration of eye doctors per population is $1 / 60,000$ and therefore within WHO's recommendations, less than $20 \%$ could independently conduct cataract surgeries. They were mostly working in urban Provincial/prefecture level hospitals. At county level in Inner Mongolia, cataract surgeries were mostly done by the visiting surgeons from Hohhot, or Beijing at the time when this survey conducted.

The most recent blindness prevalence data for the region was from the Chinese National Eye Study of 1992 [8]. It was estimated by the Regional Bureau of Health that in Inner Mongolia the annual number of cataract surgery was about 10,000 in 2010, while there were about 50,000 cataract blindness backlog in the region. In huge contrast, in the 16 years from 1988 to 2004, on average less than 7000 cataract surgeries were performed annually in Inner Mongolia. The estimated CSR was 435 in Inner Mongolia in 2009.

Tuoketuo County Hospital serves 200,000 people. It was the only one with an independent eye department amongst all the hospitals in the county. The 3 eye doctors in the department without other paramedical staff, were doing less than 20 cataract surgeries a year before the non-government organization started a project in August 2010. Shangdu County Hospital serves 342,000 people. There were 4 eye doctors in the EENT department without any nurses, or optometrists. One doctor was doing few cataract surgeries without knowing the results in 2010. There were no outreach activities from the hospital. Doctors from Beijing were invited to do one to two days cataract surgeries annually in the recent years.

The survey was designed to assess the prevalence of blindness, visual impairment and cataract service delivery situation in these two areas as the baseline data collection of a prevention of blindness project, supported by an international non-government organization and the local health authorities in Inner Mongolia.

\section{Methods}

\subsection{Ethical Approval}

Ethical approval for the survey was attained from all local project partners, including the Inner Mongolia Red 
Cross Chaoju Eye Hospital-Hohhot, Tuoketuo County Hospital and Shangdu County Hospital. Verbal consent was obtained from every study subject before eye examinations were undertaken. Survey teams were trained to demonstrate respect and kindness towards the local villagers while conducting the survey. All the cataract eyes with VA $<6 / 60$ found during this study were offered free surgeries one month after the survey, subsidized partially through the NGO project.

\subsection{Sample Size and Selection}

The latest RAAB software (version 4.03-in multi-language including Chinese) was used to calculate sample size. As the RAAB methodology required a population of 50,000 to 2,000,000, both Counties were treated as one district for sample size calculation. The Census data from the local bureau of police from the previous year was used to estimate the population of people aged 50 years and older in the two counties, and local eye care professionals provided an estimated prevalence of blindness for people aged 50 years and over (3.5\%). Based on these inputs, a sample size of 4100 participants (82 clusters of size 50) was calculated to have enough power with a variation of $20 \%$ or less and confidence of $95 \%$, assuming a non-compliance of $10 \%$.

Although the total population of Shangdu County was almost double that of Tuoketuo County, Census data indicated that Tuoketuo County has a much older age structure than that in Shangdu and therefore the number of people aged 50 years and over was very similar in both Counties-59,000 in Tuoketuo and 55,000 in Shangdu Counties. As the RAAB only includes people aged 50 years and over, the distribution of sample clusters was therefore similar between the two counties-42 of the 82 clusters were selected from Tuoketuo and the remaining 40 from Shangdu.

\subsection{Training of the Study Teams}

There were four study teams (two per County) for the RAAB, simultaneously undertaking data collection. Each team consisted of an ophthalmologist, a nurse, an administrator and a driver. The four teams received five days training together in Hohhot immediately prior to the survey. The training covered: the background and principles of RAABs; calculation of sample size; selection of clusters; inter-observer variation (IOV); how to complete the survey form; examination of subjects and practice in the field. Variations identified during IOV were examined and the junior doctors were supervised by more experienced doctors during the first week of field work, to ensure RAAB implementation was consistent with the training and theory. The training was conducted by an international trainer (Dr. Hans Limburg) with Chinese interpretation and simultaneous English and Chinese slide shows.

Prior to data collection, the heads or party secretaries from all survey villages w were invited for a half day meeting to be briefed on the purpose of the study and cooperation needed from the villagers. In consultation with these village leaders, a schedule for data collection was established and clear protocol for contact and informing selected participants.

\subsection{Ophthalmic Examination}

The village leader was contacted again the day prior to data collection in the selected village, and a refresher provided by the study team on the purpose and concepts of the RAAB. The village leader then acted as guide for the study team in the village. A random start-point was selected by the study team, who then moved from house to house in one direction. A spinning bottle was used to choose the direction at each turn of the road. In each of the 82 survey villages, house visits continued until 50 people aged 50 years and over were examined (one cluster). If the study subjects were not at the house, other family members or neighbors were asked to help arrange examination appointments for later in the day. The subjects were treated as missed cases only if the team had made three home visits or were certain the study subjects were not available.

The WHO's definition of blindness (BL), severe visual impairment (SVI) and moderate visual impairment (MVI) were used for the study [9]. Blindness is defined as VA $<3 / 60$ in the better eye with pinhole correction (Best Corrected Vision Acuity-BCVA). SVI is VA $\geq 3 / 60-<6 / 60$, MVI is VA $\geq 6 / 60-<6 / 18$. A tumbling "E" chart was used at 6 meters/ 3 meters or closer to measure the VA in good illumination by a trained nurse.

The tools used in the eye examination were torch, ophthalmoscope and portable slit lamp. Respondents with VA below 6/18 in either eye were examined again inside the house by the ophthalmologist, and causes were 
identified according to the WHO's eye diseases classification. In some cases, the pupil was dilated to increase the quality of assessment. For all respondents who had already undergone cataract surgery (including those with VA above 6/18), details such as the cataract surgical time, place, lens type (intraocular or other) and the result were assessed. Respondents who were assessed as needing cataract surgery but had not received the surgery were asked for the reasons.

\subsection{Data Input and Analysis}

Data were double entered into the Chinese version RAAB software each day after completion of one survey cluster, by the team ophthalmologist and nurse. Consistency checks and data cleaning were completed by the study coordinator (BX). The reports were generated automatically from the RAAB software. Confidence intervals were calculated using "Excel 2007” software.

\section{Results}

The examination rate was high in both counties, 96.4\% (1976 out of 2050) in Tuoketuo and 98.8\% (1975 out of $2000)$ in Shangdu. Of those missed, in Tuoketuo, 68 (3.3\%) were not available, $1(0.05 \%)$ refused and 5 (0.2\%) were not capable of being examined, while in Shangdu, with a higher examination rate, there were only 19 (0.95\%) not available, $6(0.3 \%)$ were not capable and no subjects refused.

Age and gender composition in the sample population generally represented that of the survey area in Tuoketuo and Shangdu (Table 1).

The prevalence of bilateral blindness (BCVA) in both Tuoketuo and Shangdu was low, 1.2\% (95\% CI: 0.7\% $1.7 \%$ ) and 1.4\% (95\% CI: 1.0\% - 1.9\%) respectively (Table 2). Prevalence of SVI in both counties was almost equal to that of blindness, while the MVI prevalence (4.4\% and $4.6 \%$ respectively in Tuoketuo and Shangdu) was three times higher than the blindness rate in both counties. $X^{2}$-test found no significant difference $(p>0.5)$ between male and female blindness prevalence rates in Tuoketuo, or SVI and MVI in both counties, although the teams found more females were blind, SVI or MVI in the study.

Results were extrapolated to identify the age and gender adjusted prevalence of blindness and visual impairment in the two Counties. In Tuoketuo it was estimated that there were approximately 1543 people aged 50 years old or above were bilaterally blind; 1696 with severe visual impairment and 4696 with moderate visual impairment. In Shangdu, it was estimated that there were 851 blind people aged 50 or above, 1103 with severe visual impairment and 2438 with moderate visual impairment.

Cataract was still the leading cause of blindness (62.5\% in Tuoketuo and $46.7 \%$ in Shangdu respectively) and SVI in both counties (Table 3). Uncorrected refractive error was the major cause of MVI, $50.6 \%$ in Tuoketuo and $46.2 \%$ in Shangdu, followed by cataract. Of all the blindness, SVI and MVI, $76.5 \%$ to $95.8 \%$ were treatable or preventable (avoidable) in both counties.

About half of all people with VA $<6 / 60$ requiring cataract surgery had received surgeries (Table 4). If Cataract Surgical Coverage (CSC) was calculated on eyes, less than one third of the eyes that needed surgery had

Table 1. Age and gender composition of survey area and sample population.

\begin{tabular}{|c|c|c|c|c|c|c|c|c|}
\hline \multirow{3}{*}{$\begin{array}{l}\text { Age group } \\
\text { (years) }\end{array}$} & \multicolumn{4}{|c|}{ Tuoketuo } & \multicolumn{4}{|c|}{ Shangdu } \\
\hline & \multicolumn{2}{|c|}{ Survey area } & \multicolumn{2}{|c|}{ Sample } & \multicolumn{2}{|c|}{ Survey area } & \multicolumn{2}{|c|}{ Sample } \\
\hline & $n=1976$ & $\%$ & $\mathrm{n}=55,050$ & $\%$ & $n=1975$ & $\%$ & $\mathbf{n}$ & $\%$ \\
\hline $50-54$ & 296 & $15.0 \%$ & 14,294 & $26.0 \%$ & 336 & $17.0 \%$ & 13,782 & $23.4 \%$ \\
\hline $55-59$ & 450 & $22.8 \%$ & 9934 & $18.0 \%$ & 447 & $22.6 \%$ & 15,327 & $26.0 \%$ \\
\hline $60-64$ & 345 & $17.5 \%$ & 9541 & $17.3 \%$ & 392 & $19.8 \%$ & 8997 & $15.3 \%$ \\
\hline $65-69$ & 238 & $12.0 \%$ & 8518 & $15.5 \%$ & 268 & $13.6 \%$ & 5765 & $9.8 \%$ \\
\hline $70-74$ & 261 & $13.2 \%$ & 6427 & $11.7 \%$ & 279 & $14.1 \%$ & 5779 & $9.8 \%$ \\
\hline $75-79$ & 261 & $13.2 \%$ & 3891 & $7.1 \%$ & 173 & $8.8 \%$ & 5470 & $9.3 \%$ \\
\hline $80-99$ & 125 & $6.3 \%$ & 2445 & $4.4 \%$ & 80 & $4.1 \%$ & 3772 & $6.4 \%$ \\
\hline
\end{tabular}


Table 2. Sample prevalence of blindness, SVI and MVI in Tuoketuo and Shangdu County-unadjusted.

\begin{tabular}{|c|c|c|c|c|c|c|c|c|c|}
\hline \multirow{2}{*}{ Tuoketuo county } & \multicolumn{3}{|c|}{ Male (n = 939) } & \multicolumn{3}{|c|}{ Female $(n=1037)$} & \multicolumn{3}{|c|}{ Total $(n=1976)$} \\
\hline & $\mathbf{n}$ & $\%$ & $95 \%$ CI & $\mathbf{N}$ & $\%$ & 95\%CI & $\mathbf{n}$ & $\%$ & $95 \% \mathrm{CI}$ \\
\hline \multicolumn{10}{|l|}{ Blindness (pinhole correction) } \\
\hline All bilateral blindness $(\mathrm{BCVA}<3 / 60)$ & 8 & $0.9 \%$ & $(0.3 \%-1.4 \%)$ & 16 & $1.5 \%$ & $(0.8 \%-2.3 \%)$ & 24 & $1.2 \%$ & $(0.7 \%-1.7 \%)$ \\
\hline All blind eyes & 56 & $3.0 \%$ & $(1.9 \%-4.1 \%)$ & 85 & $4.1 \%$ & $(2.9 \%-5.3 \%)$ & 141 & $3.6 \%$ & $(2.8 \%-4.4 \%)$ \\
\hline \multicolumn{10}{|l|}{ Severe visual impairment (SVI) } \\
\hline All bilateral SVI $(\mathrm{BCVA}<6 / 6 / 60, \geq 3 / 60)$ & 9 & $1.0 \%$ & $(0.3 \%-1.6 \%)$ & 11 & $1.1 \%$ & $(0.4 \%-1.7 \%)$ & 20 & $1.0 \%$ & $(0.6 \%-1.5 \%)$ \\
\hline All SVI eyes & 27 & $1.4 \%$ & $(0.7 \%-2.2 \%)$ & 39 & $1.9 \%$ & $(1.1 \%-2.7 \%)$ & 66 & $1.7 \%$ & $(1.1 \%-2.2 \%)$ \\
\hline \multicolumn{10}{|l|}{ Moderate VI (pinhole) } \\
\hline All bilateral MVI $(\mathrm{VA}<6 / 18, \geq 6 / 60)$ & 34 & $3.6 \%$ & $(2.4 \%-4.8 \%)$ & 53 & $5.1 \%$ & $(3.8 \%-6.5 \%)$ & 87 & $4.4 \%$ & $(3.5 \%-5.3 \%)$ \\
\hline All MVI eyes & 93 & $5.0 \%$ & $(3.6 \%-6.3 \%)$ & 129 & $6.2 \%$ & $(4.8 \%-7.7 \%)$ & 222 & $5.6 \%$ & $(4.6 \%-6.6 \%)$ \\
\hline Shangdu county & & \multicolumn{2}{|c|}{ Male $(n=980)$} & \multicolumn{3}{|c|}{ Female $(n=995)$} & \multicolumn{3}{|c|}{ Total $(n=1975)$} \\
\hline \multicolumn{10}{|l|}{ Blindness (pinhole correction) } \\
\hline All bilateral blindness (BCVA < 3/60) & 9 & $0.9 \%$ & $(0.3 \%-1.5 \%)$ & 19 & $1.9 \%$ & $(1.1 \%-2.8 \%)$ & 28 & $1.4 \%$ & $(1.0 \%-1.9 \%)$ \\
\hline All blind eyes & 58 & $3.0 \%$ & $(1.9 \%-4.0 \%)$ & 90 & $4.5 \%$ & $(3.2 \%-5.8 \%)$ & 148 & $3.7 \%$ & $(2.9 \%-4.6 \%)$ \\
\hline \multicolumn{10}{|l|}{ Severe visual impairment (SVI) } \\
\hline All bilateral SVI (PVA $<6 / 6 / 60, \geq 3 / 60$ ) & 16 & $1.6 \%$ & $(0.8 \%-2.4 \%)$ & 24 & $2.4 \%$ & $(1.5 \%-3.4 \%)$ & 40 & $2.0 \%$ & $(1.4 \%-3.4 \%)$ \\
\hline All SVI eyes & 40 & $2.0 \%$ & $(1.2 \%-2.9 \%)$ & 49 & $2.5 \%$ & $(1.5 \%-3.4 \%)$ & 89 & $2.3 \%$ & $(1.6 \%-2.9 \%)$ \\
\hline \multicolumn{10}{|l|}{ Moderate VI (pinhole) } \\
\hline All bilateral MVI $(\mathrm{VA}<6 / 18, \geq 6 / 60)$ & 36 & $3.7 \%$ & $(2.5 \%-4.9 \%)$ & 55 & $5.5 \%$ & $(3.1 \%-7.0 \%)$ & 91 & $4.6 \%$ & $(3.7 \%-5.5 \%)$ \\
\hline All VI eyes & 97 & $4.9 \%$ & $(3.6 \%-6.3 \%)$ & 129 & $6.5 \%$ & $(5.0 \%-8.0 \%)$ & 226 & $5.7 \%$ & $(4.7 \%-6.7 \%)$ \\
\hline
\end{tabular}

Table 3. Causes of bilateral blindness and bilateral visual impairment with available correction.

\begin{tabular}{|c|c|c|c|c|c|c|c|c|c|c|c|c|}
\hline \multirow[b]{4}{*}{ Refractive error } & \multicolumn{6}{|c|}{ Tuoketuo } & \multicolumn{6}{|c|}{ Shangdu } \\
\hline & \multirow{2}{*}{\multicolumn{2}{|c|}{$\begin{array}{l}\text { Blindness } \\
\qquad n=24\end{array}$}} & \multirow{2}{*}{\multicolumn{2}{|c|}{$\begin{array}{c}\text { SVI } \\
\mathbf{n}=20\end{array}$}} & \multirow{2}{*}{\multicolumn{2}{|c|}{$\begin{array}{c}\text { MVI } \\
\mathbf{n}=\mathbf{8 7}\end{array}$}} & \multirow{2}{*}{\multicolumn{2}{|c|}{$\begin{array}{l}\text { Blindness } \\
\qquad \mathbf{n}=\mathbf{3 0}\end{array}$}} & \multirow{2}{*}{\multicolumn{2}{|c|}{$\begin{array}{c}\text { SVI } \\
n=40\end{array}$}} & \multirow{2}{*}{\multicolumn{2}{|c|}{$\begin{array}{c}\text { MVI } \\
\mathbf{n}=91\end{array}$}} \\
\hline & & & & & & & & & & & & \\
\hline & 0 & $0.0 \%$ & 5 & $25.0 \%$ & 44 & $50.6 \%$ & 2 & $6.7 \%$ & 7 & $17.5 \%$ & 42 & $46.2 \%$ \\
\hline Aphakia, uncorrected & 0 & $0.0 \%$ & 0 & $0.0 \%$ & 0 & $0.0 \%$ & 0 & $0.0 \%$ & 0 & $0.0 \%$ & 1 & $1.1 \%$ \\
\hline Cataract, untreated & 15 & $62.5 \%$ & 10 & $50.0 \%$ & 28 & $32.2 \%$ & 14 & $46.7 \%$ & 13 & $32.5 \%$ & 23 & $25.3 \%$ \\
\hline Total treatable & 15 & $62.5 \%$ & 15 & $75.0 \%$ & 72 & $82.8 \%$ & 16 & $53.3 \%$ & 20 & $50.0 \%$ & 66 & $72.5 \%$ \\
\hline Other corneal opacity & 1 & $4.2 \%$ & 0 & $0.0 \%$ & 1 & $1.1 \%$ & 6 & $20.0 \%$ & 3 & $7.5 \%$ & 2 & $2.2 \%$ \\
\hline Myopic retinopathy & 3 & $12.5 \%$ & 2 & $10.0 \%$ & 4 & $4.6 \%$ & 0 & $0.0 \%$ & 10 & $25.0 \%$ & 8 & $8.8 \%$ \\
\hline Total preventable & 4 & $16.7 \%$ & 2 & $10.0 \%$ & 5 & $5.7 \%$ & 6 & $20.0 \%$ & 13 & $32.5 \%$ & 10 & $11.0 \%$ \\
\hline Cataract surgical complications & 2 & $8.3 \%$ & 1 & $5.0 \%$ & 2 & $2.3 \%$ & 0 & $0.0 \%$ & 1 & $2.5 \%$ & 1 & $1.1 \%$ \\
\hline Glaucoma & 2 & $8.3 \%$ & 0 & $0.0 \%$ & 1 & $1.1 \%$ & 1 & $3.3 \%$ & 1 & $2.5 \%$ & 0 & $0.0 \%$ \\
\hline Diabetic retinopathy & 0 & $0.0 \%$ & 0 & $0.0 \%$ & 0 & $0.0 \%$ & 0 & $0.0 \%$ & 0 & $0.0 \%$ & 2 & $2.2 \%$ \\
\hline Total avoidable & 23 & $95.8 \%$ & 18 & $90.0 \%$ & 80 & $92.0 \%$ & 23 & $76.7 \%$ & 35 & $87.5 \%$ & 78 & $85.7 \%$ \\
\hline ARMD & 0 & $0.0 \%$ & 0 & $0.0 \%$ & 3 & $3.4 \%$ & 0 & $0.0 \%$ & 1 & $2.5 \%$ & 6 & $6.6 \%$ \\
\hline Other posterior segment & 1 & $4.2 \%$ & 1 & $5.0 \%$ & 3 & $3.4 \%$ & 5 & $16.7 \%$ & 4 & $10.0 \%$ & 7 & $7.7 \%$ \\
\hline Globe abnormality/CNS & 0 & $0.0 \%$ & 1 & $5.0 \%$ & 1 & $1.1 \%$ & 2 & $6.7 \%$ & 0 & $0.0 \%$ & 0 & $0.0 \%$ \\
\hline
\end{tabular}


Table 4. Cataract surgical coverage in Tuoketuo and Shangdu County.

\begin{tabular}{|c|c|c|c|c|c|c|c|}
\hline & & \multicolumn{3}{|c|}{ Tuoketuo } & \multicolumn{3}{|c|}{ Shangdu } \\
\hline & & Male & Female & Total & Male & Female & Total \\
\hline \multirow[t]{2}{*}{ Blindness } & Persons (\%) & $57.1 \%$ & $50.0 \%$ & $51.7 \%$ & $66.7 \%$ & $42.9 \%$ & $52.2 \%$ \\
\hline & Eyes (\%) & $25.6 \%$ & $31.3 \%$ & $29.1 \%$ & $43.2 \%$ & $19.6 \%$ & $30.1 \%$ \\
\hline \multirow[t]{2}{*}{ SVI } & Persons (\%) & $36.4 \%$ & $44.0 \%$ & $41.7 \%$ & $54.5 \%$ & $37.5 \%$ & $44.4 \%$ \\
\hline & Eyes (\%) & $19.2 \%$ & $27.0 \%$ & $23.8 \%$ & $34.0 \%$ & $15.0 \%$ & $23.4 \%$ \\
\hline \multirow[t]{2}{*}{ MVI } & Persons (\%) & $21.1 \%$ & $28.9 \%$ & $26.3 \%$ & $47.4 \%$ & $22.6 \%$ & $32.0 \%$ \\
\hline & Eyes (\%) & $11.8 \%$ & $19.2 \%$ & $15.9 \%$ & $23.2 \%$ & $9.4 \%$ & $15.2 \%$ \\
\hline
\end{tabular}

been operated for all blindness, SVI and MVI in the two counties. These indicators showed the backload of cataract in the Counties.

In both counties, approximately half of the cataract operated eyes had good results (VA $>6 / 18$ ), but over one in five cataract operated eyes had poor visual outcome (Table 5). These results were far below the WHO's recommended quality cataract surgical outcome, which recommends the proportion of good outcome (presenting VA) being over $85 \%$, increased to $95 \%$ by correction. In both study counties, with pinhole correction, visual outcomes could be slightly improved, mainly in the eyes with IOLs implanted.

Of the poor cataract surgical outcomes, $59.6 \%$ in Tuoketuo County were due to surgical complication and over half in Shangdu County were due to sequelae.

Those with VA of less than 6/18 caused by cataract in the better eye were asked the reasons of not being operated (Table 6). In Tuoketuo, half responded that they felt no need, and a quarter said they were unaware of treatment was possible. Cost accounted for $12.9 \%$ of the barriers to surgery in the County. In Shangdu, $55.6 \%$ of the un-operated cataract patients were unaware of treatment possible, and cost was a barrier for $14.8 \%$. A further of $14.8 \%$ potential patients were denied treatment by the provider in Shangdu. This was discussed with the local doctors and answers were that because the local surgeons were not confident with the operations and had to wait for visiting surgeons. That would lead to mutual misunderstanding between the doctors and patients. In both counties, fear of surgery was an important barrier to respondents seeking treatment ( $5.6 \%$ and $9.3 \%$ respectively in Tuoketuo and Shangdu).

\section{Discussion}

The rapid assessment of avoidable blindness (RAAB) in Tuoketuo and Shangdu Counties in Inner Mongolia, China, in August and September 2010, documented a lower than expected prevalence of blindness, severe visual impairment and moderate visual impairment. The major cause of blindness and SVI was cataract, and the leading cause of MVI was uncorrected refractive errors in both study areas.

Cataract surgical coverage was low in both Counties, especially when calculated on eyes (compared to respondents) and amongst respondents with SVI and MVI. The cataract surgical outcome rate was well below than that recommended by WHO. These findings should attract much attention to the eye surgical quality control in the study areas, although the results included both recent surgeries and those performed long before current microsurgery was available. Those operated over 10 years before had worse results because of technical and facility limitations.

Eye care public health promotion and health education in these two Counties have the potential to increase access to cataract surgeries by addressing the main barriers to surgery - being unaware of the services available, and not feeling that the surgery is needed. Cost was also one of the major barriers to potential patients in the study counties, although this will become less an issue as the new Chinese rural cooperation medical insurance scheme will cover $75 \%$ of the medical cost if the service is provided at County hospital level.

After training by expert (HL), the purpose and methodology of the study were clear to everyone so that the study teams went to the field for data collection without difficulties. The study coordination was conducted by an International Non-government Organization with good eye health survey experiences. The study had also gained great support from local eye care professionals as well as the bureau of health. These all ensured the 
Table 5. Cataract surgical outcome in sample with corrections.

\begin{tabular}{|c|c|c|c|c|c|c|c|c|c|c|c|c|}
\hline & \multicolumn{6}{|c|}{ Tuoketuo } & \multicolumn{6}{|c|}{ Shangdu } \\
\hline & \multicolumn{2}{|c|}{ IOLs eyes } & \multicolumn{2}{|c|}{ Non IOLs eyes } & \multicolumn{2}{|c|}{ All eyes } & \multicolumn{2}{|c|}{ IOLs eyes } & \multicolumn{2}{|c|}{ Non IOLs eyes } & \multicolumn{2}{|c|}{ All eyes } \\
\hline & $\mathbf{n}$ & $\%$ & $\mathbf{n}$ & $\%$ & $\mathbf{n}$ & $\%$ & $\mathbf{n}$ & $\%$ & $\mathbf{n}$ & $\%$ & $\mathbf{n}$ & $\%$ \\
\hline \multicolumn{13}{|c|}{ Available corrected } \\
\hline Good & 12 & $70.6 \%$ & 2 & $15.4 \%$ & 14 & $46.7 \%$ & 13 & $76.5 \%$ & 1 & $12.5 \%$ & 14 & $56.0 \%$ \\
\hline Borderline & 2 & $11.8 \%$ & 3 & $23.1 \%$ & 5 & $16.7 \%$ & 2 & $11.8 \%$ & 3 & $37.5 \%$ & 5 & $20.0 \%$ \\
\hline Poor & 3 & $17.6 \%$ & 8 & $61.5 \%$ & 11 & $36.7 \%$ & 2 & $11.8 \%$ & 4 & $50.0 \%$ & 6 & $24.0 \%$ \\
\hline \multicolumn{13}{|c|}{ Best corrected } \\
\hline Good & 12 & $70.6 \%$ & 2 & $15.4 \%$ & 14 & $46.7 \%$ & 14 & $82.4 \%$ & 1 & $12.5 \%$ & 15 & $60.0 \%$ \\
\hline Borderline & 3 & $17.6 \%$ & 3 & $23.1 \%$ & 6 & $20.0 \%$ & 1 & $5.9 \%$ & 3 & $37.5 \%$ & 4 & $16.0 \%$ \\
\hline Poor & 2 & $11.8 \%$ & 8 & $61.5 \%$ & 10 & $33.3 \%$ & 2 & $11.8 \%$ & 4 & $50.0 \%$ & 6 & $24.0 \%$ \\
\hline
\end{tabular}

Note: Good result: Can see 6/18, Borderline: Cannot see 6/18, can see 6/60; Poor: Cannot see 6/60.

Table 6. Barriers to cataract surgery, as indicated by persons in sample, with VA < 6/60.

\begin{tabular}{|c|c|c|c|c|c|c|c|c|}
\hline \multirow{3}{*}{ Barriers } & \multicolumn{4}{|c|}{ Tuoketuo } & \multicolumn{4}{|c|}{ Shangdu } \\
\hline & \multicolumn{2}{|c|}{ Bilateral } & \multicolumn{2}{|c|}{ Unilateral } & \multicolumn{2}{|c|}{ Bilateral } & \multicolumn{2}{|c|}{ Unilateral } \\
\hline & $\mathbf{n}$ & $\%$ & $\mathbf{n}$ & $\%$ & $\mathbf{n}$ & $\%$ & $\mathbf{n}$ & $\%$ \\
\hline Need not felt & 12 & $57.14 \%$ & 27 & $50.00 \%$ & 1 & $4.76 \%$ & 2 & $3.70 \%$ \\
\hline Fear & 0 & $0.00 \%$ & 3 & $5.56 \%$ & 3 & $14.29 \%$ & 5 & $9.26 \%$ \\
\hline Cost & 5 & $23.81 \%$ & 7 & $12.96 \%$ & 4 & $19.05 \%$ & 8 & $14.81 \%$ \\
\hline Treatment denied by provider & 1 & $4.76 \%$ & 3 & $5.56 \%$ & 1 & $4.76 \%$ & 8 & $14.81 \%$ \\
\hline unaware treatment is possible & 2 & $9.52 \%$ & 14 & $25.93 \%$ & 11 & $52.38 \%$ & 30 & $55.56 \%$ \\
\hline Cannot access treatment & 1 & $4.76 \%$ & 0 & $0.00 \%$ & 0 & $0.00 \%$ & 0 & $0.00 \%$ \\
\hline Local reason & 0 & $0.00 \%$ & 0 & $0.00 \%$ & 1 & $4.76 \%$ & 1 & $1.85 \%$ \\
\hline All barriers & 21 & $100.00 \%$ & 54 & $100.00 \%$ & 21 & $100.00 \%$ & 54 & $100.00 \%$ \\
\hline
\end{tabular}

quality of the study. Because the study method was for rapid assessment of blindness in the field, time and equipment limited better diagnosis and adequate categorization of posterior causes of visual impairment. Another limitation of this study was that interview on causes of cataract patients not coming for surgeries might not be accurate because of time constraints because of the team moving quickly in the villages.

The survey established the baseline data was generally consistent with some other surveys in China [1] [10] in the recent years. Prevalence of blindness and visual impairment were lower than that of studies conducted many years ago [8] [11]. Prevalence established was lower than the findings from similar study in Yunan Province in 2006 (bilateral blindness prevalence was 3.7\% (95\% CI: 2.8\% - 4.6\%) [12]. It was also lower than the study results from most of provinces, but similar to that in Beijing from the China Nine-Province Eye Survey [2] in 2006. The estimates were close to the study results in Jiangxi Province in 2007, which showed prevalence of blindness was from $1.4 \%$ to $1.8 \%$ in the three study areas [1]. The Beijing Eye Study and Handan Eye study estimated lower prevalence of blindness in people of younger age group [13] [14]. This study findings were consistent of the findings from other similar eye studies in China and had been used for prevention of blindness planning tools in Inner Mongolia.

The RAAB gave robust evidence of blindness, MVI and SVI baseline, the cataract surgical coverage and outcomes, the barriers to cataract services. The information gives the local blindness prevention policy makers and interested INGOs good program intervention references. The whole survey could be done involving local pro- 
fessionals through proper training of the study teams.

\section{Conclusion}

The rapid assessment of avoidable blindness (RAAB) in Inner Mongolia estimated a comparatively low prevalence of blindness and over $75 \%$ of them were avoidable. This indicates eye services capacity including eye care education should be still improved in the study areas. Better planning and targeting should be set from the findings for both government and service suppliers.

\section{Acknowledgements}

The authors acknowledge Dr. Junzhen Liu, Dr. Ping Huang, Dr. Jianhua Ding, the nurses and other staff from Tuoketuo and Shangdu County for their contribution to the field data collection, and substantial support in the administration arrangements for the survey.

\section{Funding}

The study received full finance support from The Fred Hollows Foundation.

\section{Conflicts of Interest}

None of the authors have any proprietary interests or conflicts of interest in relation to this submission.

\section{References}

[1] Xiao, B., Kuper, H., Guan, C.h., Bailey, C. and Limburg, H. (2010) Rapid Assessment of Avoidable Blindness in Three Counties, Jiangxi Province, China. British Journal of Ophthalmology, 94, 1437-1442. http://dx.doi.org/10.1136/bjo.2009.165308

[2] Zhao, J.L., Ellwein, L.B., et al. (2010) Prevalence of Vision Impairment in Older Adults in Rural China, the China Nine-Province Survey. The American Academy of Ophtalmology, 117, 409-416. http://dx.doi.org/10.1016/j.ophtha.2009.11.023

[3] Pascolini, D. and Mariotti, S.P. (2012) Global Estimates of Visual Impairment: 2010. The British Journal of Ophthalmology, 96, 614-618. http://dx.doi.org/10.1136/bjophthalmol-2011-300539

[4] World Health Organization (2011) The Fact Sheet No. 282. Bulletin of the World Health Organization, April 2011.

[5] (2010) Program and Policy Implications, Today’s Research on Aging. Issue 20.

[6] http://www.nhfpc.gov.cn/

[7] Inner Mongolia Year Book 2005.

[8] Zhang, S.Y., et al. (1992) National Epidemiological Survey of Blindness and Low Vision in China. Chinese Medical Journal, 105, 603-608.

[9] World Health Organization (1988) Coding Instruction for the WHO/PBL Eye Examination Record (Version III), Geneva; WHO. WHO Document, PBL/88.1.

[10] Zhao, J., et al. (2010) Prevalence and Outcomes of Cataract Surgery in Rural China the China Nine-Province Survey. Ophthalmology, 117, 2120-2128. http://dx.doi.org/10.1016/j.ophtha.2010.03.005

[11] Zhao, J.L., Jia, L.J., Sui, R.F. and Ellwein, L.B. (1998) Prevalence of Blindness and Cataract Surgery in Shunyi County, China. American Journal of Ophthalmology, 126, 506-514. http://dx.doi.org/10.1016/S0002-9394(98)00275-X

[12] Wu, M., Yip, J.L. and Kuper, H. (2008) Rapid Assessment of Avoidable Blindness in Kunming, China. Ophthalmology, 115, 969-974. http://dx.doi.org/10.1016/j.ophtha.2007.08.002

[13] Liang, Y.B., et al. (2008) Prevalence and Causes of Low Vision and Blindness in a Rural Chinese Adult Population: The Handan Eye Study. Ophthalmology, 115, 1965-1972. http://dx.doi.org/10.1016/j.ophtha.2008.05.030

[14] Xu, L., et al. (2006) Prevalence of Visual Impairment among Adults in China: The Beijing Eye Study. American Journal of Ophthalmology, 141, 591-593. http://dx.doi.org/10.1016/j.ajo.2005.10.018 
Scientific Research Publishing (SCIRP) is one of the largest Open Access journal publishers. It is currently publishing more than 200 open access, online, peer-reviewed journals covering a wide range of academic disciplines. SCIRP serves the worldwide academic communities and contributes to the progress and application of science with its publication.

Other selected journals from SCIRP are listed as below. Submit your manuscript to us via either submit@scirp.org or Online Submission Portal.
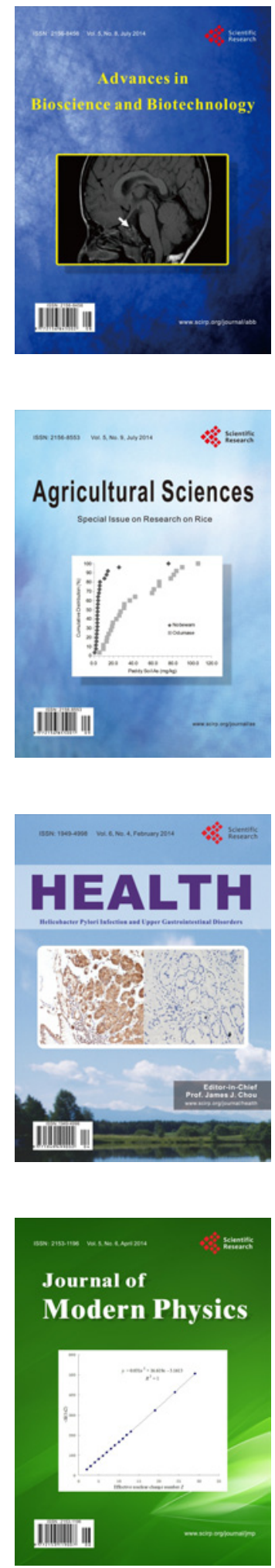
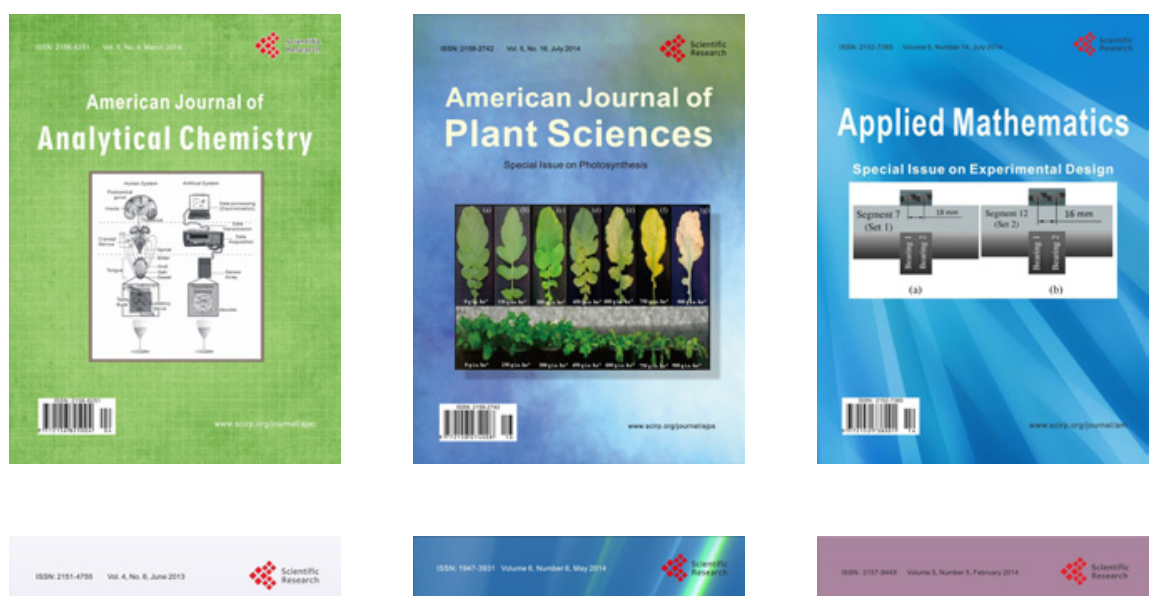

Creative Education
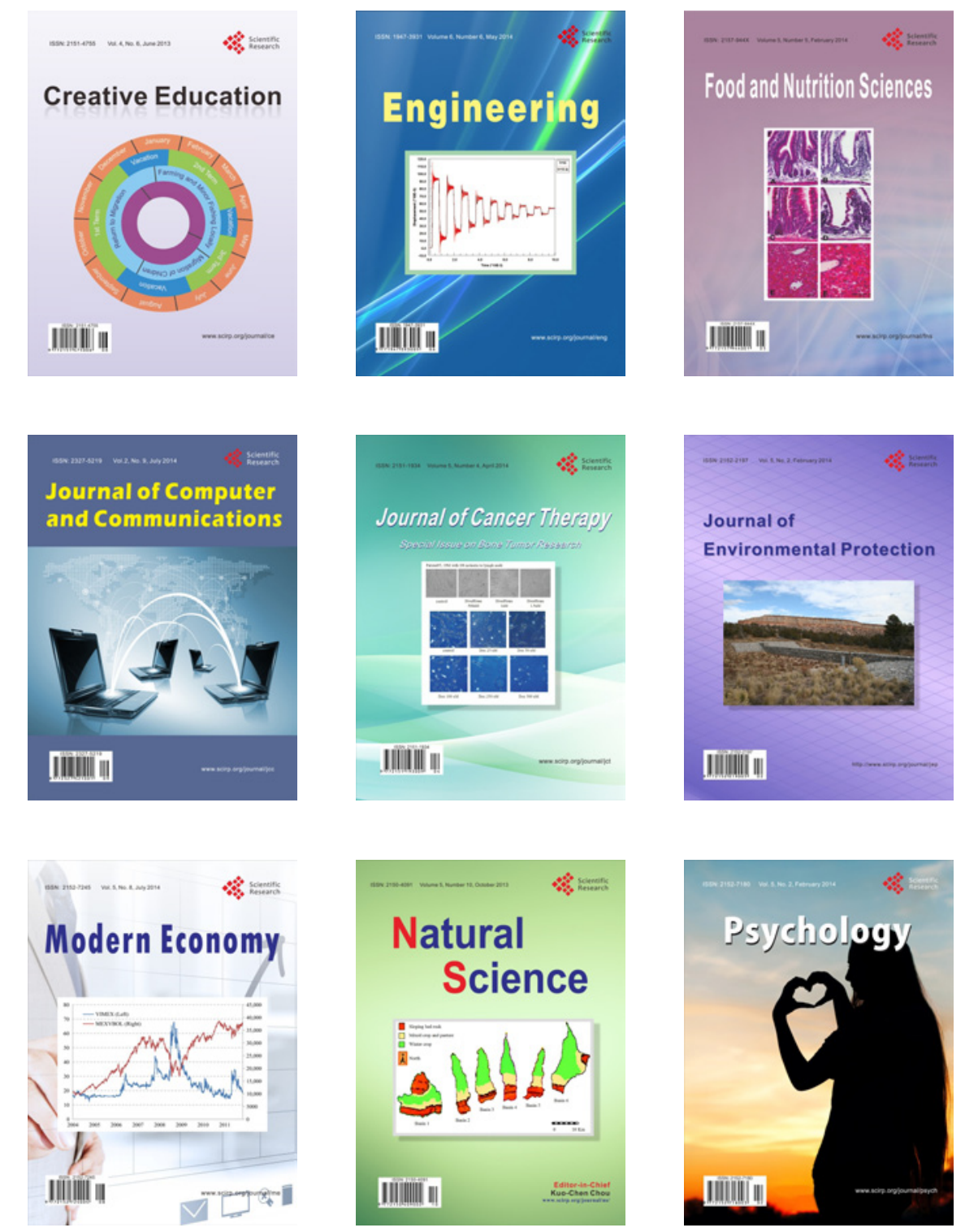